\title{
Do Caos Mercantilista à Racionalidade de Saúde: A Reconstrução do Processo Assistencial
}

\section{Juan S. Yazlle Rocha*}

O tema proposto às nossas considerações nesta mesa redonda apresenta grande atualidade e importância num contexto de risco de dispersão em neodisciplinas (como essa neo-saúde-pública chamada Vigilância em Saúde) que ameaça a unidade do campo da Saúde Coletiva. Penso que é fundamental problematizar esta questão incluindo o escopo de cada nova área e as implicações resultantes no processo de constituição e desenvolvimento do Sistema Único de Saúde. A respeito do tema a nós proposto: A Epidemiologia e as Práticas de Saúde Pública, entenderei o termo Práticas de Saúde Pública incluindo também práticas de assistência médica nos serviços e ações de saúde. Até muito recentemente a tradição no país era a total separação entre a Epidemiologia/Saúde Pública e a Assistência Médica. A associação da Epidemiologia/Saúde Pública com a Assistência Médica já demonstrou a sua eficiência no saneamento e controle e muitas doenças endêmicas, em várias regiões do país. Descontadas algumas experiências, como a dos Serviços Especiais de Saúde Pública, somente teremos tentativas de integração entre serviços de saúde pública e de assistência médica, no Estado de São Paulo, no início dos anos 70's, com a reforma da Secretaria de Estado da Saúde e a introdução da programação em Saúde, quando, ao lado das ações de saúde pública foram estruturados programas especiais de assistência médica, com organização e desenvolvimento dentro da "lógica" da epidemiologia. Esta experiência não conseguiu alterar a estruturação geral dos serviços públicos de saúde, onde a medicina previdenciaria continuou hegemônica com seu modelo privatista e mercantil de saúde. Dentro do movimento sanitário a programação em saúde

* Professor Titular de Medicina Social da Faculdade de Ribeirão Preto-USP e Ex-Secretário Municipal de Saúde de Ribeirão Preto-SP. 
foi vista com reserva como projeto limitado, reformista e racionalizador do modelo de saúde. Os programas de saúde, instituídos nos serviços estaduais, a duras penas conseguiriam apenas sobreviver. Naquela época a corrente alternativa da Saúde Pública, a Medicina Social, voltou-se ao desenvolvimento de uma Epidemiologia crítica, qualificada de Social, à margem da estrutura e organização das práticas de saúde, com as quais não visava integrar-se .

Quando a crise do modelo de saúde no país, ao final da década de 70, abriu espaço para o crescimento do Movimento da reforma Sanitária Brasileira, pensou-se que finalmente havia chegado a oportunidade para restruturar os serviços de saúde de acordo a uma lógica social embasada na Epidemiologia. Cedo percebemos que é mecânico aspirar à introdução de uma lógica "epidemiológica" na organização e desenvolvimento das práticas os serviços sociais de saúde ignorando que estes, mais do que a distribuição da saúde e das doenças, também são determinados socialmente. Desde então, temos o problema da incorporação da Epidemiologia e das práticas de saúde pública "sensu strictu" à organização e desenvolvimento de serviços de Assistência Médica no processo de construção e desenvolvimento do Sistema Único de Saúde.

Instituído legalmente o Sistema Único de Saúde, creio que o problema principal reside em conseguir agregar força social e política para impor ao conjunto de serviços de saúde o necessário ordenamento que venha caracterizá-lo, ao menos, como um Sistema de Saúde. Trata-se de superar o caos representado por uma multiplicidade de serviços e órgãos que compõem aquilo que chamamos impropriamente de SUS mas que funcionam de forma estanque, descoordenada e até competitivamente entre si. São dezenas ou centenas de serviços ambulatoriais, hospitalares, laboratoriais municipais e estaduais, púbicos estes, privados muitos outros que, absolutamente não constituem um sistema de Saúde. Os pacientes sabem disso muito bem! Eles estão sempre recomeçando um processo assistencial que se inicia na Unidade Básica de Saúde, e passa pela Distrital, por laboratórios de exames, serviço regional, hospital privado e hospital público de referência. Temos, portanto um não-sistema que funciona com a lógica do mercado de prestadores de serviços, interessados em garantir e renumerar a sua própria produtividade, sem preocupação nenhuma se todo esse imenso número de consultas, exames, procedimentos, tratamentos atende a uma racionalidade médica ou não. Este conjunto de atos e serviços está integrado e subordinado juridicamente ao que nós chamamos de SUS mas encontra-se dissociado administrativa e organizacionalmente falando. $\mathrm{O}$ processo assistencial fica recortado, descontínuo, descoordenado; é o paciente, batalhando em sucessivos retornos e serviços que luta para reconstruir o processo. Os trabalhos e trabalhadores parcelares participantes tem poucas condições de retomar, avaliar e direcionar 0 processo assistencial de forma adequada.

Até o passado recente a definição, integração e desenvolvimento do processo assistencial eram atribuições de uma instituição de saúde: na maioria das 
vezes era o hospital que desempenhava esta função. Subordinar instituições a um único comando, de preferência exercido pelo Estado, era a forma de garantir o controle, a supervisão e desenvolvimento do processo de assistência a uma dada população. Hoje o processo assistencial encontra-se fragmentado em centenas de instituições filiadas a diversos sub-sistemas públicos ou privados intra e extra hospitalares. Vivemos ainda uma fase caótica do ponto de vista da estruturação do processo assistencial.

Entretanto, temos emergente um instrumento capaz de integrar, supervisionar e controlar o conjunto dos serviços: é a informatização total da rede de serviços. Ela permitirá a re-integração do processo assistencial, a sua supervisão e controle, possibilitando o direcionamento do conjunto dos serviços, atos e procedimentos para uma racionalidade de saúde. Mais importante do que isto, talvez, é que esta integração nos permitirá, de fato, a visão e monitorização da saúde. na sua totalidade. Pela primeira vez, a totalidade sistema de saúde (excluídos os elementos supra-estruturais) deixará de ser um conceito abstrato para vir a ser uma realidade concreta. A tarefa da informatização da rede de serviços de saúde tem sido subestimada ou afastada por ser considerada excessivamente custosa ou de sofisticação desnecessária. Eu creio que as pessoas não estão suficientemente alertadas para a importância e o alcance deste recurso. Dado o caráter estratégico da informatização dos serviços de saúde eu penso que a mesma deveria ser definida urgentemente como política oficial com apoios do Ministério e das Secretarias de Estado da Saúde.

A construção do Sistema Único de Saúde dentro desta perspectiva permitirá também resgatar as práticas em saúde, epidemiológicas e de serviços, como as instâncias legítimas de geração e fundamentação do saber em saúde coletiva. Será a construção da praxis coletiva na saúde que nos permitirá a produção e desenvolvimento científico tecnológico adequado à realidade nacional com aplicação imediata na construção do SUS. Neste processo poderemos ter a oportunidade de testar nossos conceitos e objetos de trabalho, readequando e repriorizando-os; a aplicação de técnicas e métodos assinalará aqueles aptos à solução dos nossos problemas e aqueles outros que requerem de readaptação. 